\title{
Graphite block derived from natural graphite with bimodal particle size distribution
}

\author{
Byung Choon $\mathrm{Kim}^{1} \cdot$ Joon Young $\mathrm{Cho}^{2} \cdot$ Moon Hee Lee ${ }^{1} \cdot$ Joong Tark $\mathrm{Han}^{2} \cdot$ Jong Seok Woo $^{1}$ (i)
}

Received: 6 May 2020 / Accepted: 6 July 2020 / Published online: 14 July 2020

(c) Springer Nature Switzerland AG 2020

\begin{abstract}
This paper presents a novel method for the bimodal design of graphite blocks by optimizing the weight ratio of smallsized natural graphite (NG) particles (mean size of $5 \mu \mathrm{m}$ ) and large-sized NG particles (mean size of $500 \mu \mathrm{m}$ ). Graphite blocks were fabricated by subjecting a mixture containing large NG particles and a well-dispersed pitch/small-sized NG mixture (PSM) to pressure-mold heat treatment. The effect of the PSM contents on the structural, thermal, and mechanical properties of the graphite blocks was investigated. A correlation was found between the amount of small-sized NG particles, the micro-pore structure, and the distribution of large-sized NG particles. In particular, the graphite block, with small-sized NG particle content and pitch binder content of $21 \mathrm{wt} \%$ and $9 \mathrm{wt} \%$, respectively, achieved maximum thermal conductivity and flexural strength values of $460 \mathrm{~W} \mathrm{~m} \mathrm{~K}^{-1}$ and $14 \mathrm{MPa}$, respectively, after pressure-mold heat treatment (graphitization) at $2600^{\circ} \mathrm{C}$. Our research advances the development of an eco-friendly solvent-free graphite block fabrication method that produces high-performance graphite blocks of varying size faster and more cost-effectively.
\end{abstract}

\section{Graphic abstract}

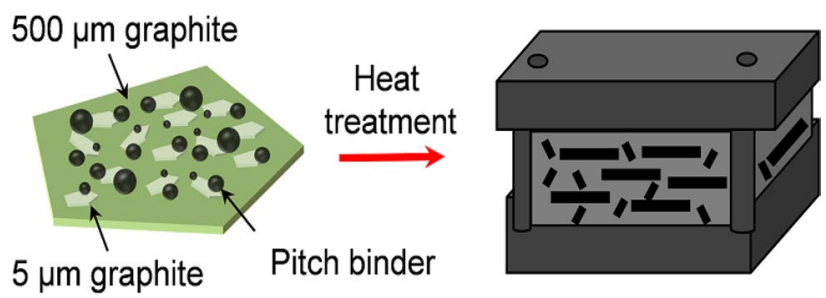

Keywords Compression molding · Carbonization · Graphitization · Pitch binder · Natural graphite

\section{Introduction}

Graphite blocks have seen extensive application in a range of modern technological devices such as electrode materials for the metallurgical industry, heat-redistribution thermal protection systems, and other high-power and high-efficiency electronic equipment [1-5]. As one of several potential heat-sink parts, carbon-based heat-dissipating materials such as the graphite block [6], carbon/ carbon composites [7, 8], carbon/metal composites [9-12],

Electronic supplementary material The online version of this article (https://doi.org/10.1007/s42452-020-3183-4) contains supplementary material, which is available to authorized users.

$\bowtie$ Joong Tark Han, jthan@keri.re.kr; $\bowtie$ Jong Seok Woo, JustinJongSeok.Woo@morganplc.com | ${ }^{1}$ Advanced Center of Engineering, Morgan Advanced Materials, 23, Dalseong2cha 4-ro, Guji-myeon, Dalseong-gun, Daegu 43013, Korea. ${ }^{2}$ Nano Hybrid Technology Research Center, Korea Electrotechnology Research Institute, Changwon 51543, Korea. 
and graphite paper [13] have been widely used because of their excellent thermal conductivity, lightweight, corrosion resistance, and high mechanical properties. To increase these properties, suitable reinforcement fillers are used with a binder (like pitch) between various carbon allotropes including graphite, carbon nanotubes, and single or multilayered graphene because of their extraordinary thermal conductivity, electrical conductivity, and mechanical properties [14-18]. Graphite blocks have been extensively studied as an important pitch-based heat-sink part due to its high in-plane thermal conductivity, low thermal expansion coefficient, good mechanical strength, and ultra-large specific surface area.

As raw material, attractive properties of natural graphite (NG), a naturally occurring form of crystalline carbon found in metamorphic and igneous rocks, include high thermal conductivity, low density, and a low thermal expansion coefficient which make it a promising thermal management material and mold lubricant, suitable for use as heat dissipation materials and refractory materials [19-22]. Carbonization refers to the conversion of any organic matter into carbon, an aspect of many different processes, while graphitization refers to the conversion of carbon into graphite that proceeds rapidly after dewrinkling of the distorted aromatic layers [23]. Theoretically, NG has extremely high thermal conductivity parallel to the graphite layers due to its planar-flake shape and lamellar crystalline structure; according to molecular dynamics simulations, the value could be as high as $2000 \mathrm{~W} \mathrm{~m}^{-1} \mathrm{~K}^{-1}$, much higher than metal $[2,5]$. In NG-filled graphite blocks, a major obstacle is the agglomeration of NG particles due to strong van der Waals interactions and poor dispersion of NG particles within the graphite block. The formation of a well-arrayed NG structure is especially important for the thermal conductivity and the flexural strength of graphite blocks. Conventionally, graphite blocks are fabricated from a pitch binder (i.e., coal tar or petroleum) and filler (i.e., coke) mixture, shaped via cold isotropic pressure or extrusion and subjected to subsequent, repeated impregnation and high-temperature (exceeding $2500{ }^{\circ} \mathrm{C}$ ) pyrolysis processes. However, the thermal conductivity of a typical graphite block using pitch binder and coke powders is as low as $70-150 \mathrm{~W} \mathrm{~m} \mathrm{~K}^{-1}$ at room temperature $[24,25]$. To increase the orientation of the carbon crystallite, efforts have been focused on hot pressing at high temperature $\left(1000-3000^{\circ} \mathrm{C}\right)$ and high pressure $(20-30 \mathrm{MPa})$. The hydrothermal carbonization method is restrictive, limiting the range of graphite block sizes. Therefore, it is necessary to develop a production process that removes the volatile components of the pitch binder during a relatively lowtemperature hot-press method, accommodates fast heat treatment, allows fabrication of variable graphite block sizes, and obviates impregnation.
The most common approach to attaining high thermal conductivity is to suspend the pitch and NG in the graphite block by using high-temperature hydrothermal carbonization. Liu et al. [26] produced a high thermally conductive graphite block containing NG and mesophase pitch using high-temperature hot pressing (at $2300-3000^{\circ} \mathrm{C}$ ). The maximum thermal conductivity and flexural strength values of $704 \mathrm{~W} \mathrm{~m}^{-1} \mathrm{~K}^{-1}$ and $21.1 \mathrm{MPa}$, respectively, were achieved when the hot-pressing temperature was $3000^{\circ} \mathrm{C}$. During heat treatment, the graphite crystallites become larger and more perfect, thereby improving the lamellar stacking structure and orientation, which significantly increases the thermal conductivity. Zhong et al. [27] achieved the highest bending strength of carbon blocks, i.e., $41.98 \mathrm{MPa}$ and thermal conductivity along the direction parallel to the graphite layers of approximately $55 \mathrm{~W} \mathrm{~m}^{-1} \mathrm{~K}^{-1}$, using a mesophase pitch content of $25 \mathrm{wt} \%$ at $1300^{\circ} \mathrm{C}$. Yuan et al. [28] fabricated graphite blocks with thermal conductivity of $522 \mathrm{~W} \mathrm{~m}^{-1} \mathrm{~K}^{-1}$ and flexural strength of 7.7 MPa from NG and mesophase pitch with low-temperature hot pressing at $500{ }^{\circ} \mathrm{C}$. In particular, He et al. [29] fabricated mixed fillers containing NG and calcined coke to form fine-grained isotropic graphite blocks using a cold isostatic pressing method. The maximum thermal conductivity of the structure increased from 93 to $130 \mathrm{~W} \mathrm{~m}^{-1} \mathrm{~K}^{-1}$ as the NG filler weight ratio increased. In these studies, pitch is normally used as a binder due to its easy graphitization. However, the arrangement of the pitch and various sized NG particles, evolution of the structure, and the relationship between structure and mechanical properties resulting from graphitization have not been systematically reported.

We demonstrate that the thermal conductivity and mechanical properties of graphite blocks were improved by using pressure-mold heat treatment, and by mixing various sized NG particles with well-dispersed pitch/ small-sized NG particle mixture (PSM) powders. Incorporating the well-dispersed PSM powders into the graphite block synergistically improved the thermal conductivity and mechanical properties. To determine the mechanisms underlying this improvement, the effect of the network pathways and bimodal particle size distribution of NG on the thermal and mechanical properties was systematically investigated along with the effect of content changes of pitch and small-sized NG particles on the mechanical properties and microstructure of the graphite blocks.

\section{Experimental}

\subsection{Materials}

The pitch binder was prepared from pyrolyzed fuel oil using a mild thermal reaction pilot-scale unit 
manufactured by Korea Research Institute of Chemical Technology. The softening point of $156.5^{\circ} \mathrm{C}$ and carbon yield of approximately $38.3 \mathrm{wt} \%$ were determined at $900{ }^{\circ} \mathrm{C}$ with a heating rate of $10^{\circ} \mathrm{C} \mathrm{min}-1$ using insoluble quinoline of approximately $1 \mathrm{wt} \%$.

The NG powders with average particle diameters of 5 um (Micrograf 99507UJ, Nacional de Grafite Ltda., Brazil) and $500 \mu \mathrm{m}$ ( $\# 3763$, Asbury Carbons, USA) and purity greater than $99 \%$ were purchased and used without further purification. The SEM images and corresponding particle size distribution of the pure NG powders are shown in Scheme 1 and S1(a)-(b) (Online Resource 1), respectively. Raman spectra were obtained using a high-resolution Raman spectrometer (US/HR-800, HORIBA Jobin-Yvon, Japan) with an excitation wavelength of $532 \mathrm{~nm}$ to characterize the microstructure of the pure NG powders. The number of defects in the NG powders was characterized by the ratio of intensities of the $D$ and $G$ bands $\left(I_{D} / I_{G}\right.$ ratio) located at 1353 and $1575 \mathrm{~cm}^{-1}$, respectively, in the Raman spectrum. The $I_{\mathrm{D}} / I_{\mathrm{G}}$ ratio of graphite particles with diameter of $5 \mu \mathrm{m}$ and $500 \mu \mathrm{m}$ was 0.19 and 0.14 , respectively [see Fig. S2a (Online Resource 1)]. Conversely, the ratio of intensities of the $2 D$ and $G$ bands $I_{2 D} / I_{G}$ for the $5 \mu \mathrm{m}$ and $500 \mu \mathrm{m}$ diameter particles was 0.43 and 0.44 , respectively, a minimal difference. The $X$-ray diffraction (XRD) patterns of the pure NG powders were obtained using a Philips PW $3830 \mathrm{X}$-ray diffractometer with Cu Ka radiation ( $\lambda=1.5418 \AA$ ) for determining interlayer spacing $\left(d_{002}\right)$, crystallite size $\left(L_{\mathrm{a}}\right)$, and crystallite height $\left(L_{c}\right)$. The $L_{c}$ and $L_{a}$ were calculated using the expressions:

$L_{c}=0.89 \lambda /\left(\beta_{002} \operatorname{Cos} \theta_{002}\right)$

$L_{\mathrm{a}}=1.84 \lambda /\left(\beta_{100} \operatorname{Cos} \theta_{100}\right)$

where $\lambda$ is the wavelength of X-ray, $\beta$ and $\theta$ are the full width at half maximum (FWHM) and Bragg angle of the diffraction peak, respectively. The $L_{c}$ value increased from 288.84 to 594.32 as the size of the NG particles increased, see Fig. S2(b) and Table S1 (Online Resource 1).

\subsection{Preparation of PSM powders and PSM/ large-sized NG particle powder mixtures (PSM/ NG)}

In order to realize a comparatively homogenous distribution of the raw materials, the pitch was micronized using an electric pulverizer (Tube Mill 100 control, IKA, Germany) at 25,000 rpm for $60 \mathrm{~s}$. The ground pitch [see Fig. S1(c) (Online Resource 1)] was subsequently mixed with the small-sized NG particles (mean size of $5 \mu \mathrm{m}$ ) with the same equipment and process to produce PSM. Finally, the large-sized NG particles (mean size of $500 \mu \mathrm{m}$ ) were added to the mixture using the electric pulverizer at $5000 \mathrm{rpm}$ for $30 \mathrm{~s}$ to produce PSM/NG. The lower speed and shorter time of the final mixing step reduce the micronizing of the $500 \mu \mathrm{m}$ particles. PSM/NG mixtures were prepared with various pitch binder contents, i.e., $7 \mathrm{wt} \%, 9 \mathrm{wt} \%, 11 \mathrm{wt} \%$, and $13 \mathrm{wt} \%$, and various small-sized $(5 \mu \mathrm{m}) \mathrm{NG}$ particle contents, i.e., 19 wt $\%, 21$ wt $\%, 22$ wt $\%, 24$ wt $\%$.

\subsection{Fabrication of PSM/NG blocks by compression molding}

The prepared PSM/NG powder mixtures were compression molded (HT-15T, ILSHIN Autoclave, Korea), dry and without mixing media, into compacted green blocks $\left(60 \times 60 \times 7 \mathrm{~mm}^{3}\right.$ in size) at $350^{\circ} \mathrm{C}$, under $35 \mathrm{MPa}$ pressure for $30 \mathrm{~min}$ inside a steel die within a uniaxial hydraulic press. The basic process and formation of the graphite blocks are illustrated in Scheme 1. Compression-induced shear stress preferentially orients the graphite grains with their basal plane perpendicular to the direction of pressure. The green blocks were subsequently placed into a heat treatment furnace under vacuum. Carbonization treatment to $\sim 1400{ }^{\circ} \mathrm{C}$ was performed (heating rate: $5^{\circ} \mathrm{C} \mathrm{min}^{-1}$ ) in order to inhibit the rapid release of volatiles, reducing the delamination or cracking of the unidirectional laminates. Carbonization was performed under different conditions, i.e., normal, where the graphite block is heated in a crucible, pressure mold, where the graphite block is heated within a pressure mold,

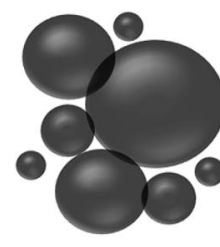

Raw pitch

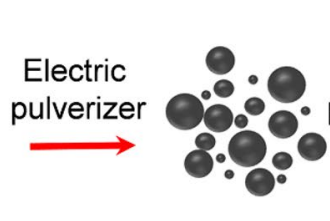

Ground pitch

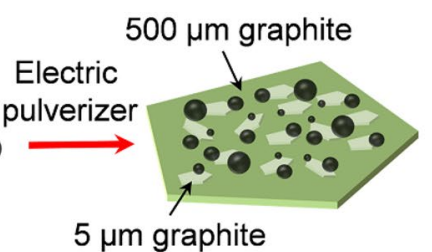

Pitch/graphite mixture powders

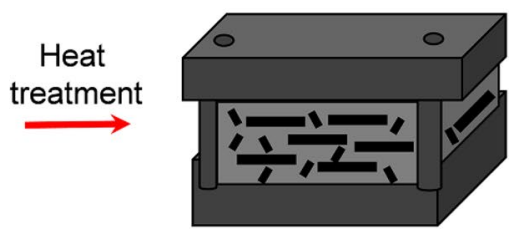

Graphite block

Scheme 1 Illustration of the PSM/NG powder mixing and graphite block formation process 
Fig. 1 a Particle size distribution curves of NG particles and ground pitch. $\mathbf{b}$ SEM image of PSM powder mixed with largesized NG particles
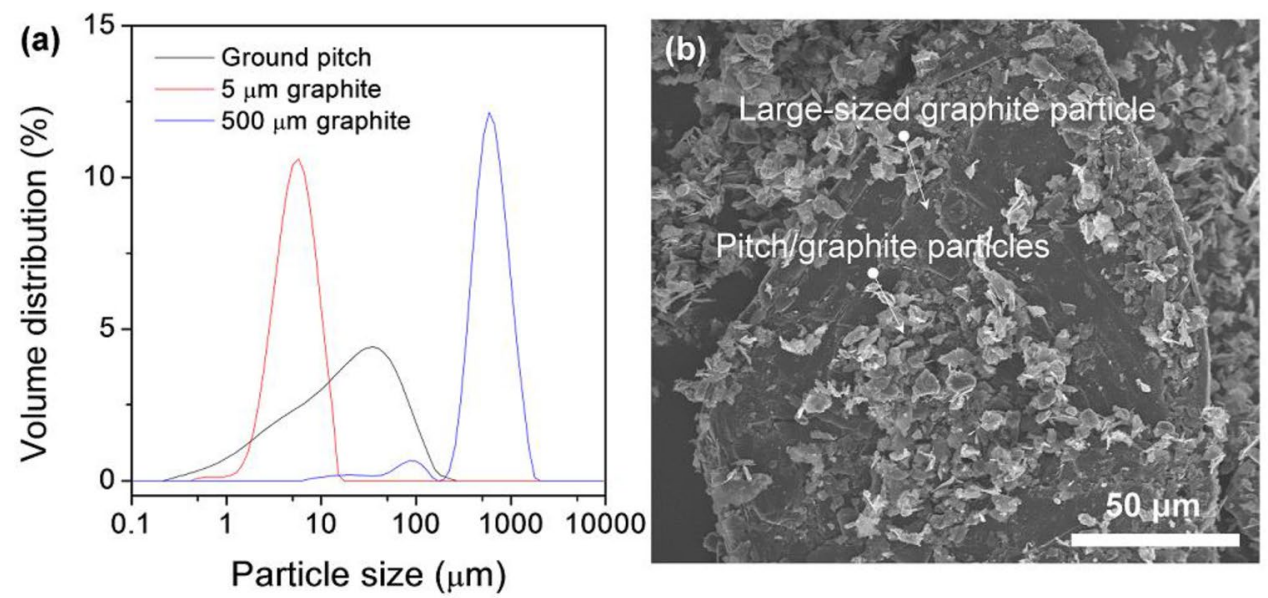

and NG bed, where the graphite block is heated while embedded in NG powder, as shown in Fig. 2.

The carbonized pressure-mold graphite blocks were subsequently graphitized, under an argon atmosphere, inside a furnace which was heated to $\sim 2600^{\circ} \mathrm{C}$, at a heating rate of $10^{\circ} \mathrm{C} \mathrm{min}^{-1}$.

\subsection{Characterization of the PSM/NG blocks}

The density and porosity of the graphite blocks were determined with the following equations:

$\operatorname{Density}\left(\mathrm{g} \mathrm{cm}^{-3}\right)=\frac{W 1}{W 2-W 3}$
Fig. 2 Photographic images of the graphite blocks carbonized under a normal, $\mathbf{b}$ pressuremold and c NG bed conditions, d The density measurements of the graphite blocks in a normal, $\mathbf{b}$ press and $\mathbf{c}$ bed, respectively. The inset images illustrate the heat treatment conditions
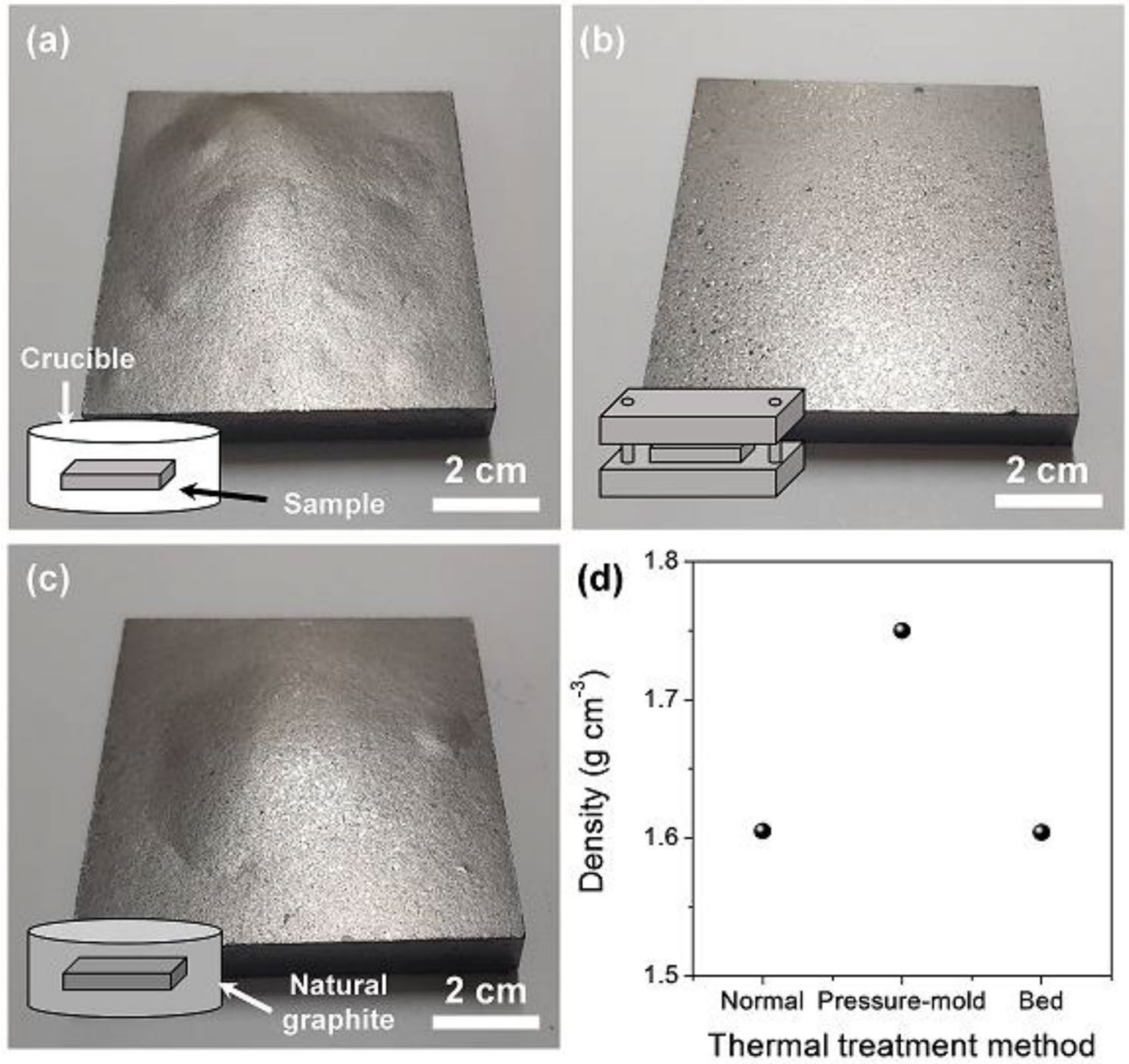
$\operatorname{Porosity}(\%)=\frac{W 2-W 1}{W 2-W 3}$

where the dried weight (W1), saturated weight (W2), and suspended weight (W3) were measured using the Archimedes' method. The particle size distribution in the PSM/ NG powder mixtures was measured with a particle size analyzer (PSA, Mastersizer 2000, Malvern, UK). The fractured surfaces and polished surfaces of the graphite blocks were observed using field-emission scanning electron microscopy (FE-SEM; S-4800, Hitachi, Japan) and optical microscopy (MA100, Nikon, Japan), respectively. Tests for thermal conductivity were performed on $10 \times 10 \times 2 \mathrm{~mm}^{3}$ $(I \times w \times h)$ samples using a thermal conductivity meter (Netzsch, LFA 457, Germany). The flexural strength of specimens was measured perpendicular to the compression direction using a universal testing machine (UTM; DECM200KC, Dawha Testing Machine, Korea); each specimen was cut to a size of $50 \times 4 \times 3 \mathrm{~mm}^{3}(I \times w \times h)$ in the international standard ASTM 790. The average flexural strength was determined from the results of five tests.

\section{Results and discussion}

\subsection{Preparation of PSM/NG blocks by compression molding}

Figure 1a shows the particle size distribution of the NG particles and pulverized pitch powder. The large raw pitch lumps (20-100 $\mathrm{mm}$ ) were pulverized to an average particle size of $30 \mu \mathrm{m}$ [see Fig. 1S(c) (Online Resource 1)]. Welldispersed PSM powders were fabricated, in which the fine pitch powder mingled with the small-sized NG particles [see Fig. S1(d) (Online Resource 1)]. Improving the particle dispersion in a graphite block in this way enhances its thermal and mechanical properties by increasing the area of interfacial interaction between the particles, as shown in Fig. 1b. Furthermore, the small-sized particles (average size $5 \mu \mathrm{m}$ ) in the PSM powder improve contact between the graphite after compression molding, further enhancing the thermal and mechanical properties.

The compression molding process was performed at $350{ }^{\circ} \mathrm{C}$ to remove the volatile components with lower molecular weight than that of the pitch binder, because these can cause the cracking or swelling of the graphite block during heat treatment. By increasing the molding temperature, the NG particles of filler and pitch binder come closer, producing a denser and more compact graphite block. The heat treatment after compression molding affects the microstructure and performance of the graphite block; the heat-treated samples containing $9 \mathrm{wt} \%$ pitch binder were investigated. After carbonization to $1400^{\circ} \mathrm{C}$, the aromatic hydrocarbons had decomposed further, polymerizing to form a zigzag or sinuous carbon layer.

We examined the graphite blocks formed under the three different processing conditions, as shown in Fig. 2a-c. The graphite blocks heated in the crucible and within the bed of NG powder, expanded during the fast heat treatment. Although high-temperature treatment can decrease the density of these graphite blocks, which improves their thermal properties, high heating rates result in the macroscopic cracks and swelling phenomena seen in Fig. 2a, c. As shown in Fig. 2d, the maximum density of $1.75 \mathrm{~g} \mathrm{~cm}^{-3}$ was achieved by the sample carbonized under pressure-mold conditions. This may have been due to the pitch binder filling the spaces between the NG particles. The lower density of the blocks in Fig. $2 a, c$ is due to cracks and micro-pores generated by the pyrolysis of the pitch binder during heat treatment.

\subsection{Effect of the pitch binder content of a PSM/ NG block on the mechanical properties and microstructure}

Controlling the content of the pitch binder is essential for the development of a graphite block with relatively low porosity and high flexural strength and thermal conductivity. Table 1 lists the physical properties of graphite blocks with various pitch contents and a constant NG particles ratio (i.e., 500:5 $\mu \mathrm{m}=80: 20$ ) fabricated using the same mixing and compression processes. The density of the graphite blocks generally decreases as the content of the pitch binder increases both before and after carbonization. This is because the lower molecular weight of pitch binder decomposes at high temperatures, resulting in the generation of gaseous species which produce porous structures within the graphite block; the greater the pitch binder content, the more gas is generated.

To evaluate the effect of pitch binder content on the degree of NG particle orientation within the plane perpendicular to the direction of compression, the fracture surfaces of graphite blocks with various pitch binder contents were characterized by SEM and optical microscopy, as shown in Fig. 3 and S3 (Online Resource 1). The optical microscopy images of cross sections parallel to the compression direction show that most NG particles are stacked parallel to each other forming a highly oriented structure, depending on the binder pitch content. The stress in the hot-pressing (compression molding) process also caused the large disk-like aromatic hydrocarbons to compress contributing to the growth and stack of graphite crystallites along the surface of the graphite flakes. A higher pitch binder content resulted in greater pitch binder agglomeration within the green body and the appearance of a 
Table 1 The properties of PSM/ NG blocks with various pitch binder contents. NG content ratio $(500: 5 \mu \mathrm{m}=80: 20)$

\begin{tabular}{|c|c|c|c|c|c|c|}
\hline \multirow{2}{*}{$\begin{array}{l}\text { Pitch } \\
\text { content } \\
\text { (wt\%) }\end{array}$} & \multirow{2}{*}{$\begin{array}{l}\text { After hot press } \\
\text { Density }\left(\mathrm{g} \mathrm{cm}^{-3}\right)\end{array}$} & \multirow[t]{2}{*}{ Carbonization $\left({ }^{\circ} \mathrm{C}\right)$} & \multicolumn{4}{|c|}{ Graphitization $\left({ }^{\circ} \mathrm{C}\right)$} \\
\hline & & & & Porosity (\%) & $\begin{array}{l}\text { Flexural } \\
\text { strength } \\
(\mathrm{MPa})\end{array}$ & $\begin{array}{l}\text { Thermal } \\
\text { conductivity } \\
\left(\mathrm{W} \mathrm{m}^{-1} \mathrm{~K}^{-1}\right)\end{array}$ \\
\hline 7 & 2.12 & Crack & & & $\mathrm{N} / \mathrm{A}$ & \\
\hline 9 & 2.07 & 1.843 & 1.800 & 13.04 & 11.6 & 437.9 \\
\hline 11 & 2.03 & 1.803 & 1.800 & 13.80 & 12.4 & 391.7 \\
\hline 13 & 2.01 & Swelling & & & $\mathrm{N} / \mathrm{A}$ & \\
\hline
\end{tabular}
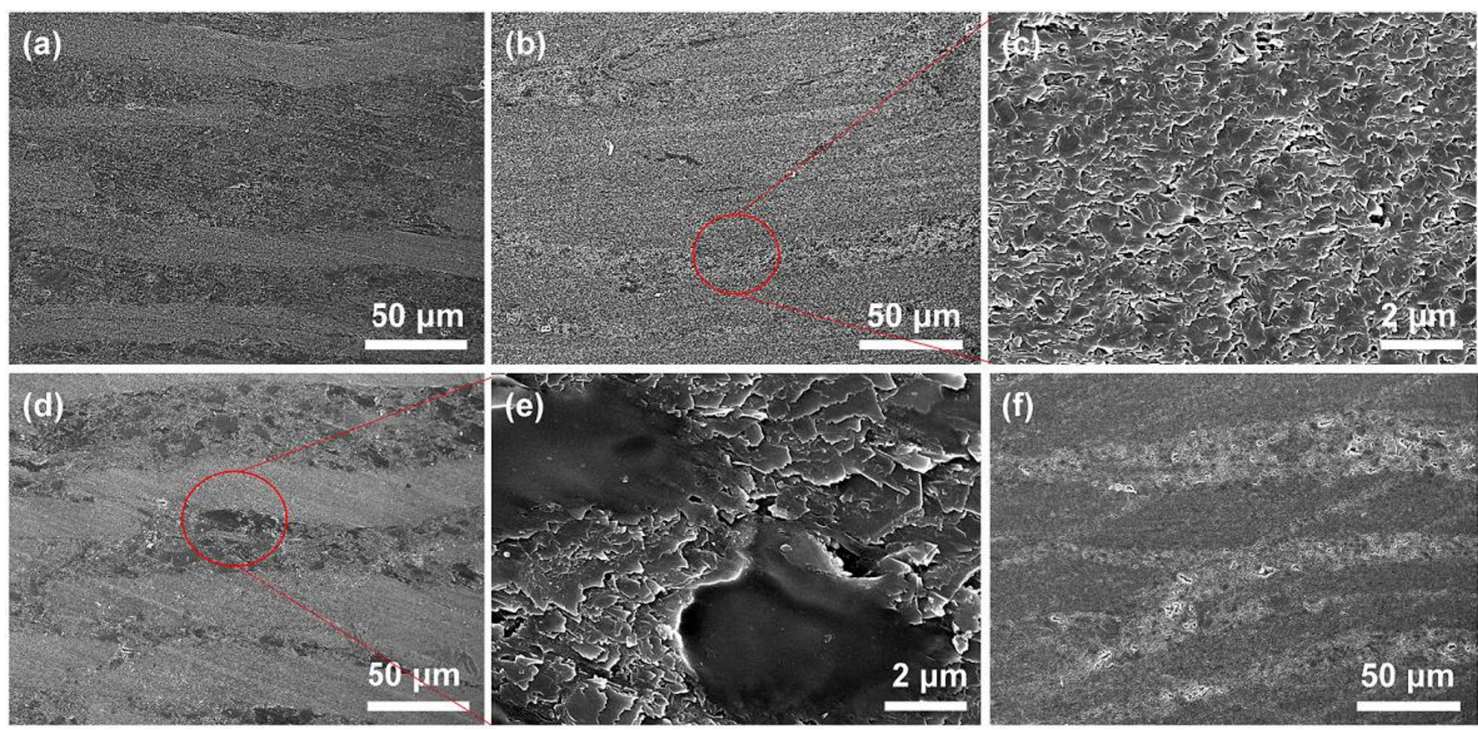

Fig. 3 SEM images of the polished fracture surface of: a the green body with 9 wt\% pitch content. b A graphite block with 9 wt\% pitch content after graphitization and $\mathbf{c}$ high-magnification image of fractured graphite block section enclosed by the red circle in $\mathbf{b}$. $\mathbf{d}$

micro-pore structure with voids between the NG particles which, under pressure (during graphitization), lead to the formation of non-oriented crystallites far away from the major planes of NG particles, as shown in Fig. 3d-f and S3 (Online Resource 1).

\subsection{Effect of the bimodal particles size distribution in PSM/NG blocks on mechanical and thermal properties}

To determine the mechanisms underlying this improvement, the effects of the network pathways and bimodal particle size distribution of NG particles on the thermal and mechanical properties were systematically analyzed as well. We examined the density and porosity of graphite block with various small-sized ( $5 \mu \mathrm{m}) \mathrm{NG}$ particle contents. Figure 4 shows the density and porosity of graphite blocks as a function of small-sized NG particle content. Smallsized NG particles act as connecting pathways between
The polished fracture surface of the green body with 11 wt\% pitch content and e high-magnification image of green body section enclosed by the red circle in $\mathbf{d}$. $\mathbf{f}$ The polished fracture surface of the graphite block with 11 wt\% pitch content after graphitization

larger NG particles effectively increasing density and decreasing porosity.

The morphology, particularly the dispersion of particles, may offer insights into the physical properties of the graphite blocks. Figure 5 shows SEM images of the surface of polished graphite blocks before and after heat treatment with various small-sized NG particle contents. The polished fracture surfaces in Fig. $6 a$, b show a connected graphite structure interspersed with small graphite particles. The internal graphitic layers of the graphite blocks after graphitization show a highly preferred orientation perpendicular to the direction of pressure employed during hot pressing. However, the smaller NG particles strongly agglomerated creating voids in the graphite blocks before and after heat treatment, see Fig. 5c-f.

The thermal conductivity of the graphite blocks is strongly correlated with orientation, dispersion, and size of the NG particles. We analyzed the thermal conductivity and flexural strength as a function of the small-sized

\section{SN Applied Sciences}



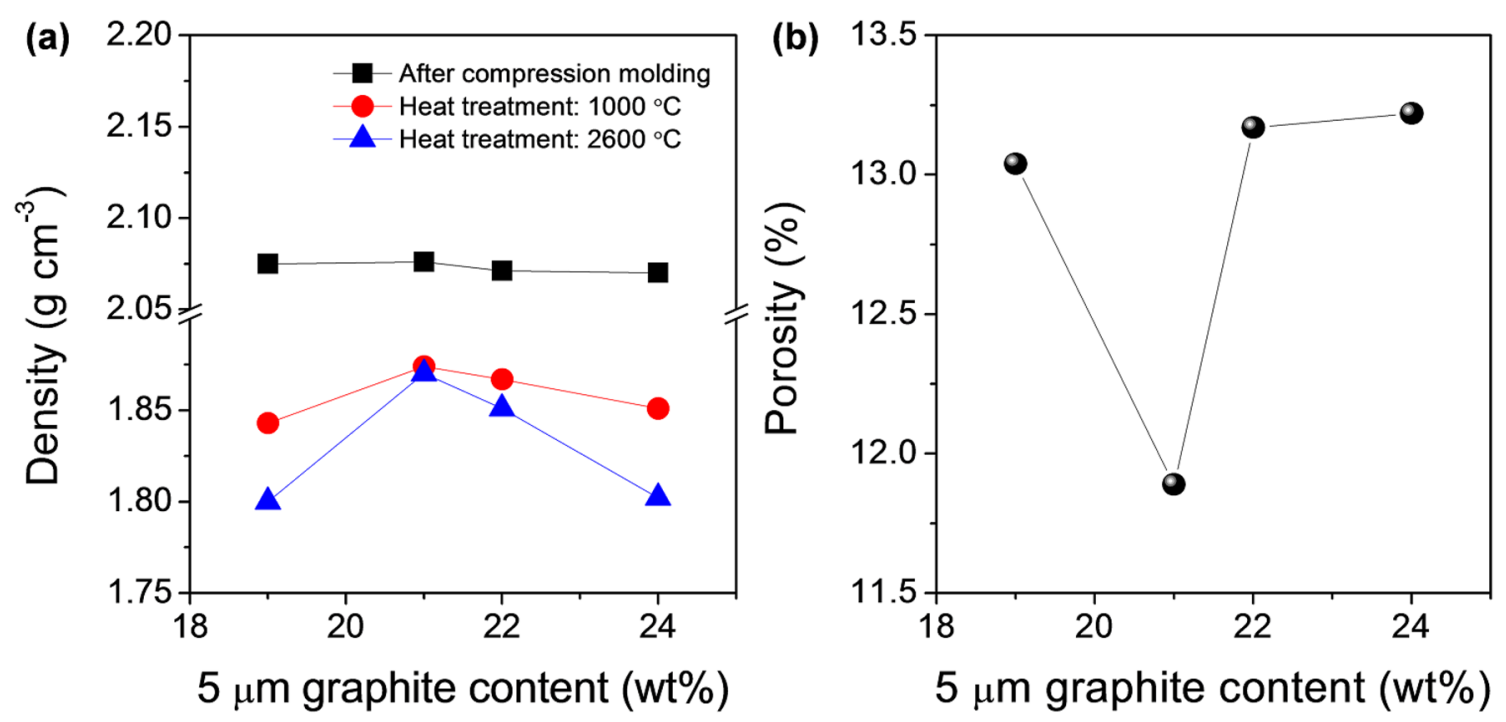

Fig. 4 Influence of small-sized NG particle (mean size of $5 \mu \mathrm{m}$ ) content on the $\mathbf{a}$ density and $\mathbf{b}$ porosity of graphite blocks

Fig. 5 SEM images of graphite blocks with various smallsized NG particle contents: a polished fracture surface of the green body with $21 \mathrm{wt} \%$ smallsized $(5 \mu \mathrm{m})$ NG particle content and $\mathbf{b}$ after graphitization. c polished fracture surface of green body with 24 wt $\%$ content, $\mathbf{d}$ high-magnification image of $\mathbf{c}$. e after graphitization, $\mathbf{f}$ high-magnification image of $\mathbf{e}$
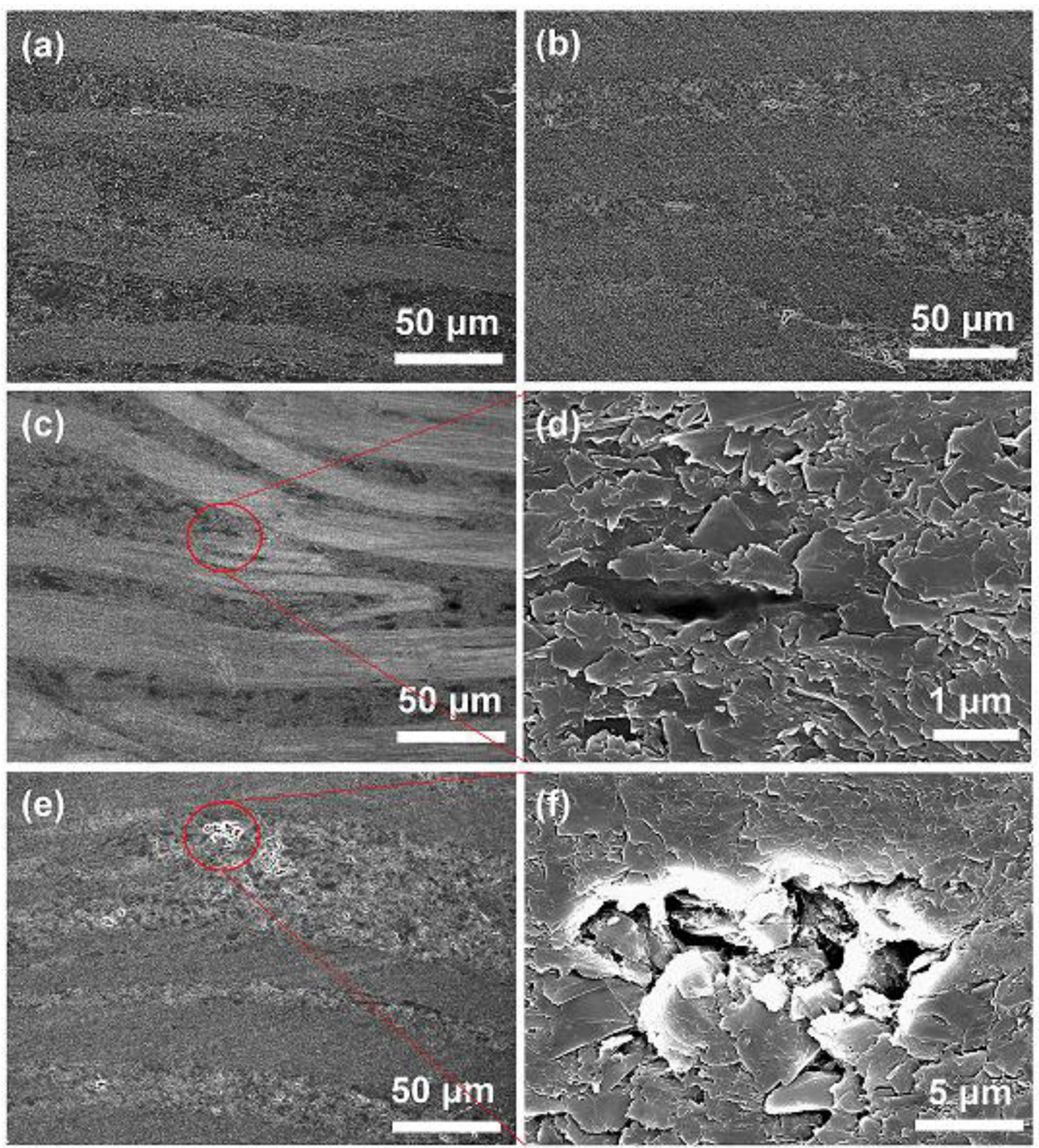

SN Applied Sciences a SPRINGer Nature journal 
NG particle content in the graphite blocks (see Fig. 6). It was believed that the $5 \mu \mathrm{m}$ NG particles in the mixture would improve the packing density of the graphite block, increasing the density and flexural strength, and reducing the porosity. After graphitization, the thermal transport properties of the graphite blocks are markedly improved. In the case of the graphite blocks graphitized at $2600^{\circ} \mathrm{C}$, the thermal conductivity and flexural strength values were as high as $460 \mathrm{~W} \mathrm{~m} \mathrm{~K}^{-1}$ and $14 \mathrm{MPa}$, respectively. Thus, in terms of dispersion, the $5 \mu \mathrm{m} N G$ particles positively affected the inter-particle conduction, enhancing the overall thermal conductivity of the graphite blocks.

\section{Conclusions}

The goal of this study was to improve the thermal conductivity and flexural strength of graphite block through bimodal optimization and pressure-mold heat treatment. It was observed that a well-dispersed PSM/NG mixture, with small-sized NG particle content and pitch binder content of $21 \mathrm{wt} \%$ and $9 \mathrm{wt} \%$, respectively, compression molded, and pressure-mold heat treated (i.e., carbonized to $\sim 1400{ }^{\circ} \mathrm{C}$ then graphitized to $\sim 2600^{\circ} \mathrm{C}$ ), achieved the best thermal conductivity and flexural strength values of $460 \mathrm{~W} \mathrm{~m} \mathrm{~K}^{-1}$ and $14 \mathrm{MPa}$, respectively. This method is commercially attractive as it can be used to produce quality graphite blocks of various sizes simply, cost-effectively, and at speed.

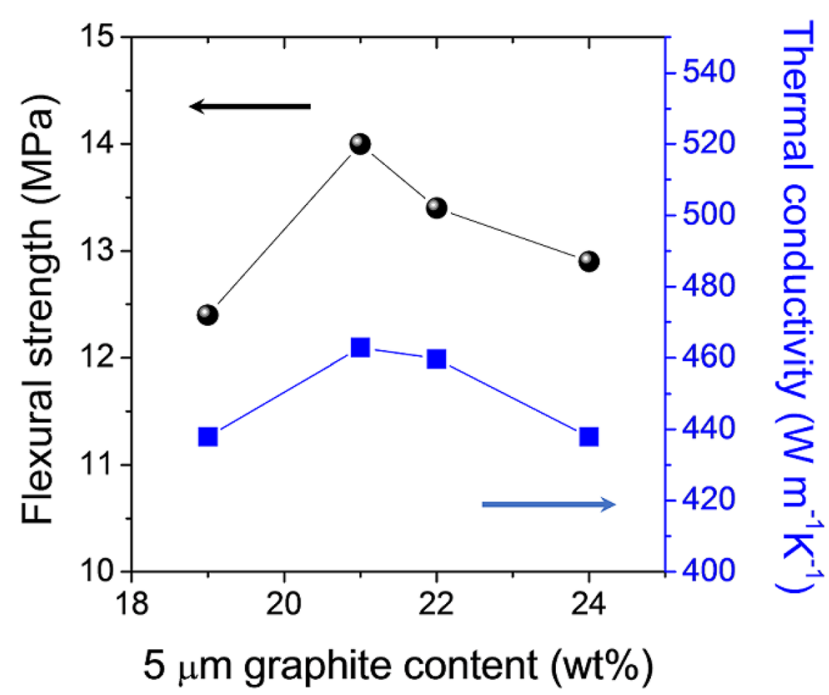

Fig. 6 Flexural strength and thermal conductivity of the graphitized graphite block as functions of the small-sized NG particle content
Acknowledgements The authors sincerely thank Dr. Ji Sun Im of the Korea Research Institute of Chemical Technology (KRICT), for providing the petroleum-based pitch used as binder.

Authors' contributions Byung Choon Kim and Joon Young Jo have contributed equally to this work.

Funding This work was supported by the Korea Evaluation Institute of Industrial Technology (KEIT-10077710, KEIT-20006696) and National Research Foundation (NRF-2016M1A2A2937163).

\section{Compliance with ethical standards}

Conflict of interest The authors declare that they have no conflict of interest.

\section{References}

1. Baskin Y, Meyer L (1955) Lattice constants of graphite at low temperatures. Phys Rev 100:544. https://doi.org/10.1103/PhysR ev.100.544

2. Inagaki M, Kaburagi $Y$, Hishiyama $Y$ (2014) Thermal management material: graphite. Adv Eng Mater 16:494-506. https:// doi.org/10.1002/adem.201300418

3. Wang $\mathrm{Q}$, Han $\mathrm{XH}$, Sommers A et al (2012) A review on application of carbonaceous materials and carbon matrix composites for heat exchangers and heat sinks. Int J Refrig 35:7-26. https:// doi.org/10.1016/j.ijrefrig.2011.09.001

4. Brooks JD, Taylor GH (1965) The formation of graphitizing carbons from the liquid phase. Carbon 3:187-193. https://doi. org/10.1016/0008-6223(65)90047-3

5. Smith AW, Rasor NS (1956) Observed dependence of the lowtemperature thermal and electrical conductivity of graphite on temperature, type, neutron irradiation, and bromination. Phys Rev 104:885. https://doi.org/10.1103/PhysRev.104.885

6. Gao Q, Jin S, Guo C et al (2015) Effects of heat-treatment temperature and binder content on the microstructure and thermal conductivity of graphite flake-carbon composites. Fuller Nanotubes Carbon Nanostruct 23:1043-1050. https://doi. org/10.1080/1536383X.2015.1060590

7. Yuan G, Li X, Dong Z et al (2014) Pitch-based ribbon-shaped carbon-fiber-reinforced one-dimensional carbon/carbon composites with ultrahigh thermal conductivity. Carbon 68:413-425. https://doi.org/10.1016/j.carbon.2013.11.018

8. Zhao Y, Liu Z, Wang H et al (2013) Microstructure and thermal/ mechanical properties of short carbon fiber-reinforced natural graphite flake composites with mesophase pitch as the binder. Carbon 53:313-320. https://doi.org/10.1016/j.carbo n.2012.11.013

9. Nazeer F, Ma Z, Gao L et al (2019) Thermal and mechanical properties of copper-graphite and copper-reduced graphene oxide composites. Compos Part B Eng 163:77-85. https://doi. org/10.1016/j.compositesb.2018.11.004

10. Cui Q, Yu C, Hao J et al (2018) Ultrahigh thermal conductivity copper/graphite membrane composites prepared by tape casting with hot-pressing sintering. Mater Lett 231:60-63. https:// doi.org/10.1016/j.matlet.2018.08.015

11. Xue C, Bai H, Tao PF et al (2016) Thermal conductivity and mechanical properties of flake graphite/Al composite with a SiC nano-layer on graphite surface. Mater Des 108:250-258. https ://doi.org/10.1016/j.matdes.2016.06.122 
12. Guardia-Valenzuela J, Bertarelli A, Carra F et al (2018) Development and properties of high thermal conductivity molybdenum carbide-graphite composites. Carbon 135:72-84. https://doi. org/10.1016/j.carbon.2018.04.010

13. Feng $\mathrm{ZH}, \mathrm{Li} \mathrm{TQ}, \mathrm{Hu} \mathrm{ZJ}$ et al (2012) Low cost preparation of high thermal conductivity carbon blocks with ultra-high anisotropy from a commercial graphite paper. Carbon 50:3943-3960. https ://doi.org/10.1016/j.carbon.2012.03.015

14. Miranda A, Barekar N, McKay BJ (2019) MWCNTs and their use in Al-MMCs for ultra-high thermal conductivity applications: a review. J. Alloys Compd 774:820-840. https://doi.org/10.1016/j. jallcom.2018.09.202

15. Hidalgo-Manrique $P$, Lei $X, X u$ R et al (2019) Copper/graphene composites: a review. J Mater Sci 54:12236-12289. https://doi. org/10.1007/s10853-019-03703-5

16. Han JT, Cho JY, Kim JH et al (2019) Structural recovery of highly oxidized single-walled carbon nanotubes fabricated by kneading and electrochemical applications. Chem Mater 31:34683475. https://doi.org/10.1021/acs.chemmater.9b00719

17. Cho JY, Kim JH, Yang HJ et al (2020) Tailored and highly efficient oxidation of various-sized graphite by kneading for highquality graphene nanosheets. Carbon 157:663-669. https://doi. org/10.1016/j.carbon.2019.10.102

18. Chung DDL (1987) Exfoliation of graphite. J Mater Sci 22:41904198. https://doi.org/10.1007/BF01132008

19. Chung DDL (2002) Review: graphite. J Mater Sci 37:1475-1489. https://doi.org/10.1023/A:1014915307738

20. Jiang W, Nadeau G, Zaghib K, Kinoshita K (2000) Thermal analysis of the oxidation of natural graphite-effect of particle size. Thermochim Acta 351:85-93. https://doi.org/10.1016/S0040 -6031(00)00416-0

21. Zhou S, Chiang S, Xu J et al (2012) Modeling the in-plane thermal conductivity of a graphite/polymer composite sheet with a very high content of natural flake graphite. Carbon 50:50525061. https://doi.org/10.1016/j.carbon.2012.06.045
22. Lee MH, Kim HY, Oh SM et al (2018) Structural optimization of graphite for high-performance fluorinated ethylene-propylene composites as bipolar plates. Int J Hydrog Energy 43:2191821927. https://doi.org/10.1016/j.ijhydene.2018.09.104

23. Oberlin A (1984) Carbonization and graphitization. Carbon 22:521-541. https://doi.org/10.1016/0008-6223(84)90086-1

24. Ishiyama S, Burchell TD, Strizak JP et al (1996) The effect of high fluence neutron irradiation on the properties of a fine-grained isotropic nuclear graphite. J Nucl Mat 230:1-7. https://doi. org/10.1016/0022-3115(96)00005-0

25. Oku T, Hiraoka T, Kuroda K (1995) Improvement of thermal conductivity of carbon materials due to addition of metal particles. J Nucl Sci Technol 32:816-818. https://doi.org/10.1080/18811 248.1995.9731778

26. Liu Z, Guo Q, Shi J et al (2008) Graphite blocks with high thermal conductivity derived from natural graphite flake. Carbon 46:414-421. https://doi.org/10.1016/j.carbon.2007.11.050

27. Zhong B, Zhao GL, Huang XX et al (2014) Binding natural graphite with mesophase pitch: a promising route to future carbon blocks. Mater Sci Eng A 610:250-257. https://doi.org/10.1016/j. msea.2014.05.038

28. Yuan G, Li X, Dong Z et al (2012) Graphite blocks with preferred orientation and high thermal conductivity. Carbon 50:175-182. https://doi.org/10.1016/j.carbon.2011.08.017

29. He Z, Lian P, Song J et al (2018) Microstructure and properties of fine-grained isotropic graphite based on mixed fillers for application in molten salt breeder reactor. J Nucl Mater 511:318-327. https://doi.org/10.1016/j.jnucmat.2018.09.039

Publisher's Note Springer Nature remains neutral with regard to jurisdictional claims in published maps and institutional affiliations. 